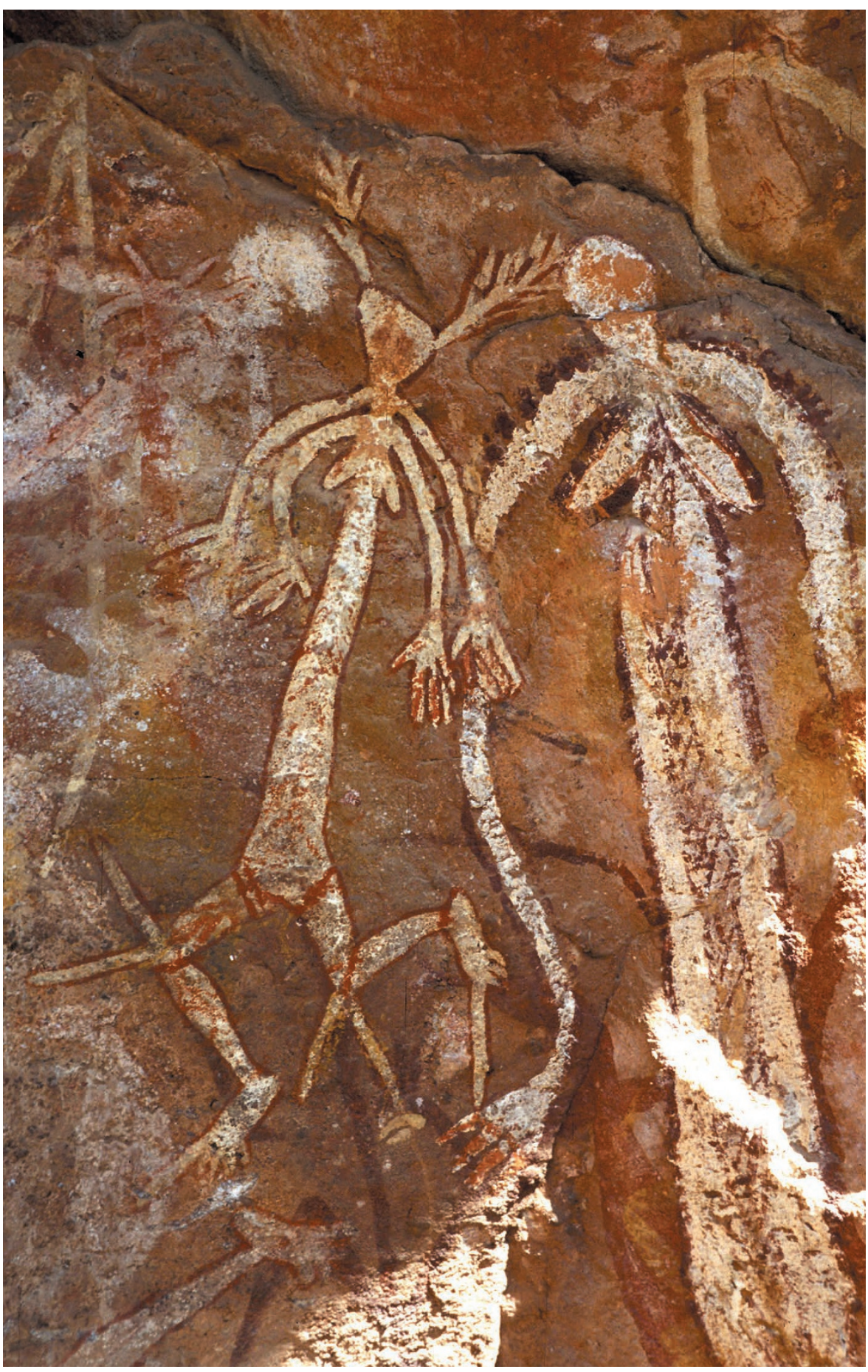

Aboriginal rock paintings at the Nanguluwur shelter in Kakadu National Park, Australia.

\section{PALAEOLITHIC ART}

\section{Old masters, early cultures}

\author{
Jill Cook examines archaeologist Jean Clottes's theories \\ about what motivated Ice Age artists.
}

S ubtle, imaginative and brilliantly accomplished, the images of animals and humans found in caves and dated from the end of the last Ice Age, between 40,000 and 10,000 years ago, continue to astonish us. The emotions and motives that inspired them beg to be understood. In What is Paleolithic Art?, Jean Clottes, the renowned cave- and rock-art specialist, suggests some answers.

After 40 years lead-

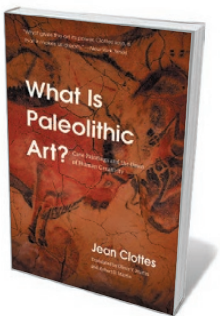

What Is Paleolithic Art?: Cave Paintings and the Dawn of Human Creativity

JEAN CLOTTES (TRANSLATED BY OLIVER Y. MARTIN AND ROBERT D. MARTIN)

University of Chicago Press: 2016.

ing research at French sites such as the Chauvet and Cosquer caves and the Volp Caverns, Clottes describes his investigations into why people adorned the walls of caves and openair rock surfaces with engravings, paintings and sculptures. His approach is challenged by some specialists, who feel that it is futile to attempt to interpret or take the investigation of cave art beyond the collation of facts that, in their view, cannot be explained except in terms of what, when, where and how.

Clottes is prepared to go further. He wants to test hypotheses developed to parsimoniously explain the majority of observed facts against the premise that the images indicate spiritual behaviours. He goes so far as to call humans Homo spiritualis, owing to our capacity to symbolize ideas beyond words and transcend realities through belief. Instead of viewing these ancient cave and rock artists as apart from us, he makes the case for using historical evidence to "detect convergences in ways of thinking or conceiving of particular aspects of reality". This is not simplistic analogy, but reasoning "based on the behaviour of analogous societies".

During the 1990s, Clottes widened his interests from European Palaeolithic sites to the rock art of other continents. At this time, he worked closely with archaeologist and ethnologist David Lewis Williams, an expert on the southern African San people and their paintings. Together, they developed a hypothesis that could account for many attributes of Pleistocene and historical rock and cave art around the world. They realized that for many traditional, non-literate peoples, the landscapes in which they live are considered to be imbued with spiritual powers; particular places, sometimes decorated with images of animals and/or symbols, are reservoirs of supernatural powers, where shamans might perform rituals to

\section{DNATURE.COM}

For more on science in culture see:

nature.com/

booksandarts 
contact, appease or exploit the spirits.

Clottes provides an overview of some of the varied beliefs and practices that he has researched, observed or been told about on visits to sites in Africa, Asia, Australasia and the Americas. He sees these "multiple realities" as part of the broad spectrum of spirituality focused in the landscape and nature. He shares his own experiences of fascinating but brief encounters with indigenous guides, such as Clifford, a venerated medicine man of the Native American Ute people. When they visited a rock-art site in Utah, a female bighorn sheep appeared. Clottes describes how Clifford chanted and made tobacco offerings, and how he later said that the sheep was "the spirit of the site" and suggested that the spot would be good for "vision-questing".

Finally, Clottes shows how such anthropological insights enrich our ability to question the Palaeolithic record and construct interpretations of behaviours, actions and events in the deep past with a better-informed historical imagination. His view is that knowledge of present and historical rockart practices can be the key to interpreting the past. Older, less rigorous applications of this thinking were rejected for being simplistic. Clottes's approach is more cautious, and he readily admits that the significance of many more-recent rock-art sites may be unknown or reinterpreted by modern aboriginal descendants.

Some readers will wonder whether it is right to view the varied social behaviours that resulted in drawing, painting and sculpture solely through the lens of belief. Others may question a search for universal traits that brings together eclectic cross-cultural similarities in spiritual practice that are fascinating but not necessarily helpful. Above all, Palaeolithic art is the first visible sign of modern human consciousness, of self-awareness, complex language, the use of metaphor and symbol, a sense of beauty, minds powered by brains like our own. Clottes offers little thought on how we might research these aspects of our deep history and what makes us human. But as neuroscience advances, this must surely be the next step.

This is a thought-provoking book about complex societies that endeavoured to understand the world in their own various ways. For anyone interested in Ice Age art, Clottes's enthusiasm cannot fail to energize, inspire and provide caution to their own investigations.

Jill Cook is acting keeper in the Department of Britain, Europe and Prehistory at the British Museum in London. Specializing in research on portable art made of bone, antler, ivory and stone, she curated the 2013 exhibition Ice Age Art: Arrival of the Modern Mind, and has written a book of the same name. e-mail:jcook@britishmuseum.org

\section{Books in brief}

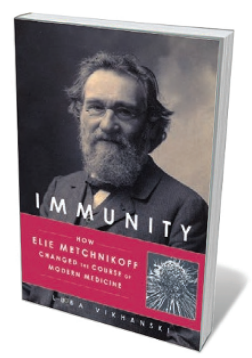

\section{Immunity: How Elie Metchnikoff Changed the Course of Modern Medicine}

Luba Vikhanski CHICAGo ReVIEW PRESS (2016)

In 1882, Russian zoologist Elie Metchnikoff discovered the mechanics of natural immunity while experimenting on starfish larvae. Physician Jules Rochard called his theory an "oriental fairy tale", yet it won Metchnikoff a share in a Nobel prize decades later. As journalist Luba Vikhanski reveals in this engrossing scientific biography, the gifted Metchnikoff's breakthroughs extended to invertebrate embryology, treatments for syphilis and pioneering research on some of today's hottest topics in biology: the microbiome, probiotics and longevity.

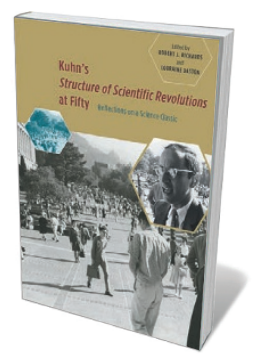

Kuhn's Structure of Scientific Revolutions at Fifty

Edited by Robert J. Richards and Lorraine Daston UNIVERSITY OF CHICAGO PRESS (2016)

Few books leave a wake like physicist-turned-historian Thomas Kuhn's The Structure of Scientific Revolutions (University of Chicago Press, 1962; see D. Kaiser Nature 484, 164-166; 2012). These essays on that classic, edited by science historians Robert Richards and Lorraine Daston, emanate from a 2012 commemorative conference. It's a scholarly treat, from George Reisch probing the cold-war roots of Kuhn's provocations on dogma, to David Kaiser tracing the experimental psychology in his philosophical claims.

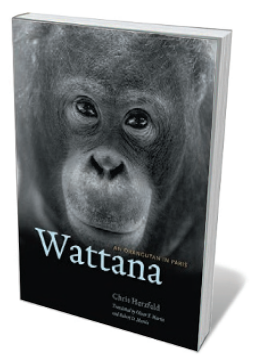

\section{Wattana: An Orangutan in Paris}

Chris Herzfeld, translated by Oliver Y. Martin and Robert D. Martin UNIVERSITY OF CHICAGO PRESS (2016)

For this thoughtful, unusual study of the human-ape 'interface', philosopher of science Chris Herzfeld focuses on a captive orang-utan, one of less than 1,000 worldwide. Zoo-born Wattana, given string, cloth and paper at the Jardin des Plantes menagerie in Paris, made elaborate knots and 'necklaces' — a skilful use of fibre unsurprising in a tree-dwelling primate that builds complex nests, yet so far seen only in captivity. A trove of gripping research, somewhat marred by its scattershot presentation.

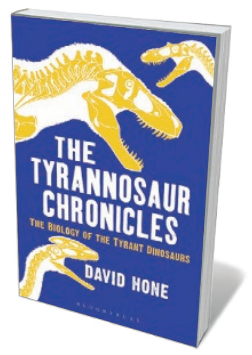

The Tyrannosaur Chronicles: The Biology of the Tyrant Dinosaurs David Hone BLOOMSBURY SIGMA (2016)

Weighing some 6 tonnes and sporting ranks of formidable serrated teeth, the tyrannosaur has bitten into the human imagination like no other creature from the Cretaceous period ending 66 million years ago. Luckily for its devotees, the fevered pace of palaeontology means that findings on 30 or so species of tyrant dinosaur are piling up fast. Ecologist David Hone's primer lays out the facts and educated guesses, from the beasts' near-global distribution to their taxonomy, anatomy, reproduction, behaviour and spectacular looks, possibly enhanced by a "mosaic" of scales, feathers and keratin folds.

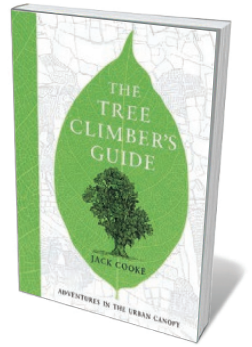

The Tree Climber's Guide: Adventures in the Urban Canopy Jack Cooke HARPERCOLLINS (2016)

Nature writing has focused mainly on the terrestrial, and sometimes the marine. With Jack Cooke's guide, it just got arboreal. An ebullient tree-climber, evoking the hominin connection to canopy life even as he mourns humanity's lack of "biaxial ball-and-socket wrist joints", Cooke exults in the sensory thrill of being aloft. But his tour of London's trees, from cedar of Lebanon to common lime, is less about racing to the top than remapping the city to reconnect us with the extraordinary worlds above our heads. Barbara Kiser 